\title{
A study of nuclear diameters in lymph node imprints using the Zeiss Microvideomat
}

\author{
J. CROCKER AND R. C. CURRAN
}

From the Department of Pathology, The Medical School, The University of Birmingham B15 2TJ, UK

SUMMARY The diameters of the cell nuclei were measured in imprint preparations of eight tonsils and 28 lymph nodes, each specimen being from a separate patient. The lymph nodes were from cases of Hodgkin's disease (HD), non-Hodgkin's lymphoma (NHL), and reactive benign states. The nuclear diameters were measured by means of an image-analysing device, the Zeiss Microvideomat. For accurate measurements, the cells had to be well separated, and tissue sections could not be used because the close juxtaposition of nuclei gave erroneous readings. However, cell imprints proved suitable. The results show that the mean nuclear diameters for the HD, NHL, and reactive groups differ and show a considerable scatter. However, the distributions for the NHL and reactive nodes are sufficiently different to suggest that the method may have diagnostic value for the former.

The classification of lymphomatous conditions is in a state of flux (Bennett et al., 1974; Lukes and Butler, 1966) and, as a result, precision in diagnosis and histological typing is still often difficult to achieve. This is unfortunate, not least because accuracy of diagnosis is often of considerable importance to the clinician managing the patient.

In diagnosing the lymphomas, pathologists already make extensive use of the sizes of cells and particularly of their nuclei. The estimates of size are, however, almost always made by direct observation; and although marked variations in size (as in the Reed-Sternberg cells of Hodgkin's disease (HD)) are readily detected, the method does not detect moderate differences nor does it give absolute measurements of size; for example, it does not readily detect whether the mean diameters of the cells or nuclei in lymphocytic lymphoma differ from those in reactive lymph nodes. To achieve this, an objective technique which measures sizes with more precision is required. The usefulness of imprints and their image analysis in cases of Sézary's syndrome has been shown previously by Van Vloten et al. (1974), and the present study describes the application of a method of measuring nuclear diameters based on the Microvideomat (Carl Zeiss Oberkochen) to a range of lymphoid tissues.

\section{Material and methods}

The tissues examined were lymph nodes and tonsils

Received for publication 20 December 1978 removed surgically, the former either as a primary diagnostic biopsy or at staging laparotomy. Each specimen examined was removed from a separate patient. In each case the mean nuclear diameter was measured by means of the Zeiss Microvideomat and correlated with the histological type.

\section{THE MICROVIDEOMAT}

In the Microvideomat a television camera tube sited above an optical microscope scans the image of the object produced by the microscope. The image is scanned line by line by the camera, and the variations in brightness of the image are converted by the camera tube into differing voltage levels. This voltage signal is then relayed to an electrical console and control panel, and displayed on a television monitor screen as an image which can be adjusted for brightness, contrast, and measurement functions.

Effectively, therefore, the light-density of the object examined in the microscope is converted to a black-and-white monitor picture, whose level of discrimination of features may be modified by a simple grey-scale. The grey-scale, used as a reference of intensity, is pre-adjusted by the operator to a level of sensitivity which corresponds to a particular feature of the object to be examined. By this means it is possible to measure the percentage of a selected field occupied by a feature discriminated in the grey-scale. A further function of the Microvideomat is that of sizing discrete objects or 'particles'. This is achieved by initially calibrating the monitor image by the use of a conventional stage micrometer. Once this has been done, objects discriminated by their 
grey-scale intensity can be examined and their displacement along a horizontal cord length compared with the calibration reference values. The number of 'particles' of each size range is electronically tagged and counted. From these results it is possible to plot a histogram showing the frequency of values for certain horizontal line diameters. A mean object diameter can then be calculated.

\section{TISSUES}

It was initially hoped that it would be possible to measure mean nuclear diameters in paraffin sections of routinely processed tissues. However, in sections of ordinary thickness $(6-8 \mu \mathrm{m})$ this proved impossible because of the considerable overlapping of cells, these being 'seen' by the Microvideomat as single, larger cells. In an attempt to overcome this problem, thin $(2 \mu \mathrm{m})$ sections were examined. In these, the cell nuclei were better separated, but a new problem was encountered in that each nucleus stained as several discrete blocks of chromatin, which the Microvideomat counted as individual small 'nuclei'. These difficulties were overcome by the use of cell imprints (Fig. 1).

Thirty-six specimens of lymphoid tissue were investigated: $28 \mathrm{lymph}$ nodes and eight tonsils, each specimen being from a separate patient. They were surgical specimens received direct from the operating theatre in the unfixed state. The types of tissue examined, their numbers, and the final diagnosis are shown in the Table.

Cell imprints were made from each of these, from 5 minutes to 2 hours after surgical removal. For delays greater than 20 minutes, the tissue was stored at $4^{\circ} \mathrm{C}$. The lymph nodes were carefully sectioned with a degreased razor blade, and the freshly cut surfaces were applied to degreased microscope slides. It was found that imprints made 10-20 minutes after operation gave the most reproducible results, with least cell disruption. There was a marked tendency for the larger cells to disrupt, particularly at the edges of the imprints. Disruption was often combined with 'tailing' of the cells, both changes presumably being caused by shearing forces at the periphery.

FIXATION AND STAINING METHODS

The imprints were fixed in one of the following solutions: (1) acetone $\left(4^{\circ} \mathrm{C}\right): 2$ minutes; (2) absolute ethanol $\left(20^{\circ} \mathrm{C}\right): 2$ minutes; (3) ether/ethanol $(50: 50 \mathrm{v} / \mathrm{v})$ mixture $\left(20^{\circ} \mathrm{C}\right): 2$ minutes; (4) $4 \%$ formaldehyde in $0.9 \% \mathrm{NaCl}$ solution $\left(20^{\circ} \mathrm{C}\right): 12$ hours; or (5) $4 \%$ formaldehyde in a $2 \%$ aqueous calcium acetate solution $\left(\mathrm{pH} 7 \cdot 0,4^{\circ} \mathrm{C}\right.$ ) (Lillie and Fullmer, 1976): 12 hours.

The imprints were then stained by one or more of the following techniques: (1) Jenner-Giemsa solu-
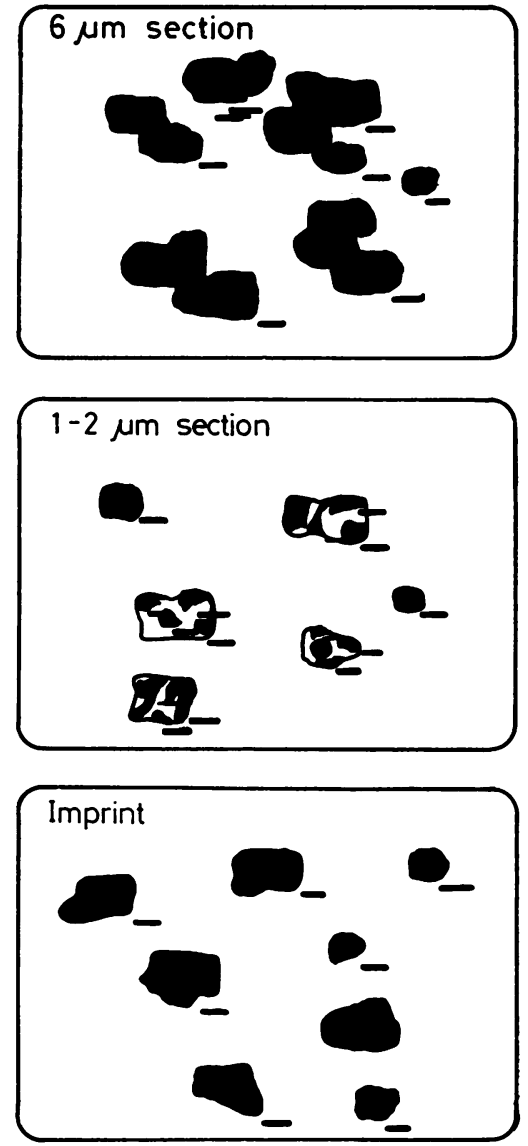

Fig. 1 Diagrammatic views of conventional tissue section (top), thin section (middle), and tissue imprint (bottom) of lymphoid tissue as seen on the screen of the Microvideomat. Electronic marker tags separate cell nuclei best in the imprint preparation.

tion; (2) Leishman method (Drury and Wallington, 1967): (3) Feulgen DNA; (4) fluorescent Feulgen DNA staining (Culling, 1974); (5) methyl green (2\% aqueous; chloroform extracted); (6) Harris's haematoxylin without counterstain; (7) Harris's haematoxylin and eosin.

Of the many combinations of fixative and staining techniques tested, the one that gave the most reliable and reproducible results and was adopted for routine use was fixation in absolute ethanol followed by staining with Harris's haematoxylin without counterstain. After careful differentiation of this stain, a good imprint from a lymph node shows well-spaced cells with clearly defined nuclei against a featureless background. 
Table Individual details of cases examined

\begin{tabular}{|c|c|c|c|c|}
\hline \multicolumn{2}{|c|}{ Histological diagnosis } & \multirow{2}{*}{ Age } & \multirow{2}{*}{$\frac{\operatorname{Sex}}{\mathrm{M}}$} & \multirow{2}{*}{$\begin{array}{l}\text { Mean nuclear diameter }(\mu \mathrm{m}) \\
8.23\end{array}$} \\
\hline Lymph n & odes HD: lymphocyte predominant & & & \\
\hline , & " HD: nodular sclerosis & 20 & $\mathbf{F}$ & $9 \cdot 01$ \\
\hline " & "HD: nodular sclerosis & 35 & $\mathbf{F}$ & $8 \cdot 91$ \\
\hline " & " HD: nodular sclerosis & 36 & $\mathbf{F}$ & Uncountable \\
\hline , & ", HD: mixed cellularity & 23 & $\mathbf{M}$ & $8 \cdot 44$ \\
\hline ", & , HD: mixed cellularity & 37 & $\mathbf{M}$ & $7 \cdot 92$ \\
\hline$"$, & ", HD: mixed cellularity & 40 & $\mathbf{M}$ & $9 \cdot 06$ \\
\hline$\because$ & " HD: mixed cellularity & 48 & $\mathbf{M}$ & $7 \cdot 60$ \\
\hline$"$ & " HD: mixed cellularity & 49 & $\mathbf{M}$ & $9 \cdot 39$ \\
\hline$"$ & " HD: mixed cellularity & 62 & $\mathbf{M}$ & $8 \cdot 47$ \\
\hline ", & " HD: lymphocyte depleted & 29 & $\mathbf{F}$ & $9 \cdot 21$ \\
\hline$"$ & $\begin{array}{l}\text { NHL: follicular lymphocytic lymphoma, } \\
\text { small cell }\end{array}$ & 61 & $\mathbf{M}$ & $10 \cdot 36$ \\
\hline$"$ & $\begin{array}{l}\text { NHL: follicular lymphocytic lymphoma, } \\
\text { small cell }\end{array}$ & 72 & $\mathbf{M}$ & $9 \cdot 83$ \\
\hline$"$ & $\begin{array}{l}\text { NHL: follicular lymphocytic lymphoma, } \\
\text { large and small cell }\end{array}$ & 47 & $\mathbf{F}$ & $9 \cdot 57$ \\
\hline$"$ & $\begin{array}{l}\text { NHL: follicular lymphocytic lymphoma, } \\
\text { large and small cell }\end{array}$ & 49 & $\mathbf{M}$ & $9 \cdot 56$ \\
\hline " & $\begin{array}{l}\text { "NHL: follicular lymphocytic lymphoma, } \\
\text { large cell }\end{array}$ & 53 & $\mathbf{M}$ & $8 \cdot 01$ \\
\hline , & $\begin{array}{l}\text { NHL: follicular lymphocytic lymphoma, } \\
\text { large cell }\end{array}$ & 69 & $\mathbf{M}$ & Uncountable \\
\hline$"$ & $\begin{array}{l}\text { NHL: diffuse lymphocytic lymphoma, } \\
\text { large and small cell }\end{array}$ & 73 & $\mathbf{F}$ & $10 \cdot 62$ \\
\hline " & $\begin{array}{l}\text { NHL: diffuse lymphocytic lymphoma, } \\
\text { large cell }\end{array}$ & 46 & $\mathbf{M}$ & $8 \cdot 92$ \\
\hline & , Reactive & 10 & $\mathbf{F}$ & $7 \cdot 36$ \\
\hline , & , Reactive & 30 & $\mathbf{F}$ & $8 \cdot 04$ \\
\hline , & , Reactive & 35 & $\mathbf{F}$ & $8 \cdot 25$ \\
\hline ", & , Reactive & $?$ & $\mathbf{F}$ & $7 \cdot 62$ \\
\hline. & , Reactive & 47 & $\mathbf{F}$ & $7 \cdot 99$ \\
\hline , & "Reactive & 68 & $\mathbf{F}$ & 6.95 \\
\hline ", & "Sarcoidosis & 25 & $\mathbf{M}$ & $8 \cdot 55$ \\
\hline , & , Sarcoidosis & 38 & $\mathbf{F}$ & $8 \cdot 15$ \\
\hline ", & " Sarcoidosis & 42 & $\mathbf{M}$ & $7 \cdot 95$ \\
\hline Tonsils & Reactive & $14-29$ & - & 8 cases $7 \cdot 27-8 \cdot 0$ \\
\hline
\end{tabular}

THE CELL SIZING PROCEDURE

For each specimen the nuclei of at least 500 cells were measured, and the mean nuclear diameter was calculated. The measurements were performed 'blind', cases being coded by number only. Where two or more nuclei were contiguous, the Microvideomat saw these as one nucleus, and areas in which the cells were clumped gave false high readings. Readings were therefore made from areas where the cell nuclei were sufficiently spaced to enable discrete sizing. From the results a frequency histogram of nuclear diameter was plotted for each case, and the mean nuclear diameter was calculated.

\section{Results}

Figure 2 comprises typical histograms of three preparations showing a representative range of nuclear diameters and their mean. Figure 3 shows the mean nuclear diameter values of the specimens examined. Extensive clumping of cells and disruption of nuclei rendered two of the 36 specimens uncountable: one was of HD and the other of non-Hodgkin's lymphoma (NHL). This problem, however, was not confined to a particular disease type. As Fig. 3 shows, the ranges for the different diseases merge at their upper and lower limits. There is, however, a difference in the size-range between the reactive lymph nodes (lymph nodes draining carcinoma and virus-stimulated nodes) and the NHL cases. The mean nuclear diameter of the reactive group is $7.72 \mu \mathrm{m}$ (SD 0.51 ) and that of the NHL group is $9.56 \mu \mathrm{m}$ (SD 0.88 ). The scatter of the HD cases is considerable and spans the reactive and NHL ranges with a mean nuclear diameter of $8.63 \mu \mathrm{m}$ (SD 0.59).

\section{Discussion}

When the Microvideomat is used to size individual 'particles', such as nuclei, two criteria must be met: the preparation must allow the nuclei to be discriminated visually and electronically in terms of grey-scale intensity; and the nuclei must be presented to the machine as discrete entities. Both these criteria were satisfied in 34 of 36 imprints studied. 


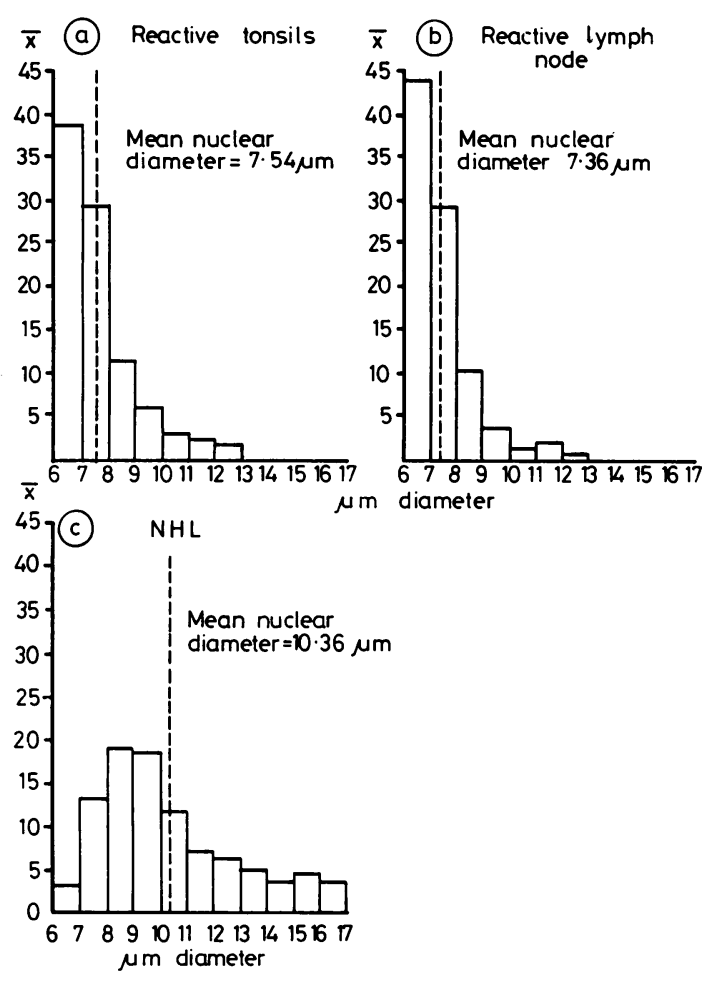

Fig. 2 (a, b, and c) Examples of typical nuclear diameter distributions in three imprint preparations. There is a wider range of diameters in the NHL specimen than in the two reactive specimens $(\bar{x}=$ mean number of cells).

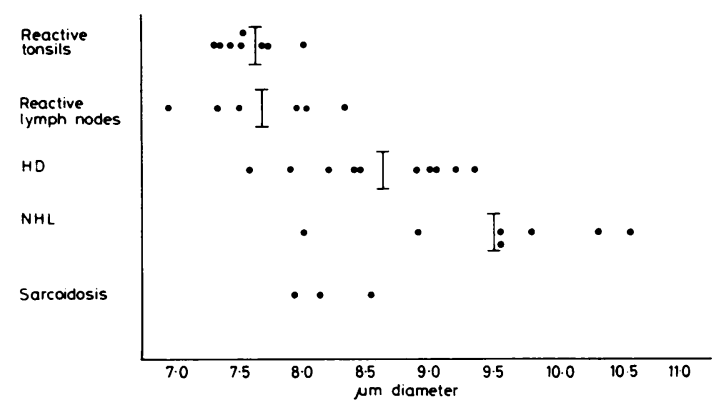

Fig. 3 Ranges of mean nuclear diameters in the specimens measured $(I=$ mean of range $)$.

The technique used in the present study is fairly simple and rapid and can readily be performed in parallel with the usual histological examination when fresh lymphoid tissue is available. The excessive cell clumping, which rendered two of the 36 specimens unsuitable for study, could probably have been overcome by taking a larger number of imprints from each lymph node. However, there are a number of other technical problems associated with the Microvideomat method which may affect the results: (1) the diameter of the whole cell rather than the nucleus alone may be measured. This was minimised or eradicated by careful differentiation of the Harris's haematoxylin nuclear stain and omission of counterstaining, as described above, so that each nucleus was well stained and well defined but the staining of the cytoplasm was minimal; (2) the cells and nuclei may alter in size during processing. By standardising rigidly the methods of fixation, staining, and processing of the imprints we aimed to make the alteration a constant one; (3) the tendency of the cells to disrupt. This tendency was reduced when the conditions of imprinting, fixation, and staining were optimal, and in any case areas showing disruption were rejected. Dixon (1964) described improved morphological stability of rat liver cells after 'limited autolysis', and our finding that a delay of 10-20 minutes between surgical removal and imprinting gave the best results may have a similar basis; (4) some types of cell may be more 'sticky' than others. If this were so, it could influence the population of cells present in the imprints and thereby the range of nuclear diameters, for example, in the HD group. There was no evidence, however, for the existence of differential 'stickiness' of the various cell types, and the wide range of diameters in HD would appear to reflect the greater heterogeneity of cell types in HD compared with reactive nodes and NHL.

The wide range of mean nuclear diameters in the HD group and its considerable overlap with reactive cases indicate that the technique has little potential diagnostic value for HD, although it is possible that in a larger series different types of HD would fall into distinct groups. In this series of cases, it can be seen that the mean nuclear diameter for each case of both HD and NHL bears surprisingly little relationship to the specific sub-type of disease. Interestingly, there is no obvious discrepancy between the range for sclerotic and cellular types of HD. However, the considerable difference between the NHL cases and reactive nodes does assist in differentiating between these two groups. The difficulties that arise in the overlap area between the ranges of the reactive lesions and the NHL should be readily overcome by combining the results with histology. It is appreciated that the Microvideomat is nonselective in its measurement of nuclear sizes. This is probably a considerable limitation, and it may well be that the sizing of individual cell or nuclear populations might reveal some very interesting data.

A combination of histology and measurement of nuclear diameter should be especially helpful in the 
differentiation between reactive follicular hyperplasia and follicular lymphocytic lymphoma.

We are indebted to Mrs Jean Fitzmaurice and Miss Mary Domone for technical assistance and to Miss Valerie Esland for typing the manuscript.

\section{References}

Bennett, M. H., Farrer-Brown, G., Henry, K., and Jelliffe, A. M. (1974). Classification of non-Hodgkin's lymphomas (Letter). Lancet, 2, 405-406.

Culling, C. F. A. (1974). Handbook of Histopathological and Histochemical Techniques, 3rd edition, pp. 615-616. Butterworth, London.

Dixon, K. C. (1964). Rolled films of dying liver cells. British Journal of Experimental Pathology, 45, 481-487.
Drury, R. A. B., and Wallington, E. A. (1967). Carleton's Histological Technique, 4th edition, pp. 311-312. Oxford University Press, London.

Lillie, R. D., and Fullmer, H. M. (1976). Histopathologic Technic and Practical Histochemistry, 4th edition, pp. 33-34. McGraw-Hill, New York.

Lukes, R. J., and Butler, J. J. (1966). The pathology and nomenclature of Hodgkin's disease. Cancer Research, 26, 1063-1083.

Van Vloten, W. A., Van Duijn, P., and Schaberg, A. (1974). Cytodiagnostic use of Feulgen-DNA measurements in cell imprints from the skin of patients with mycosis fungoides. British Journal of Dermatology, 91, 365-371.

Requests for reprints to: Dr J. Crocker, Department of Pathology, The University of Birmingham Medical School, Birmingham B15 2TJ, UK.

The Journal of Clinical Pathology is to conform to a uniform style for submitted manuscripts, details of which are set out in the article on page 744, reprinted, with the permission of the editor, from the British Medical Journal of 24 February 1979. Authors are requested in future to submit all manuscripts in the new style, and the change-over will take effect in the January 1980 issue of this journal. 